\title{
Research on Information Dissemination of Colleges and Universities based on PDCA algorithm
}

\author{
Haiyan Wang ${ }^{1 a}$, Liying $\mathrm{Cao}^{2 \mathrm{~b}}$ \\ ${ }^{1}$ Higher Education Research Institute, Jilin Agricultural University, Changchun, China, 130118; \\ ${ }^{2}$ College of Information and Technology Science, Jilin Agricultural University, China, 130118

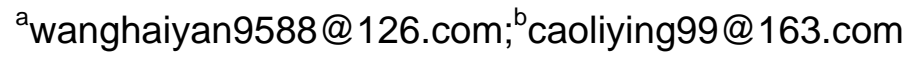

Keywords: Information Dissemination; PDCA algorithm; management method; Internet

\begin{abstract}
Abstract: under the network environment, social networking sites and a variety of network information service providers to attract more and more users, plays an important role in the exchange of information and communication. In this paper, through the analysis of students under the network environment of the information demand and the network communication tools, the comparison of characteristics of different kinds of network communication tools, the establishment of the subject status of the proposed library under the network environment.
\end{abstract}

\section{Introduction}

The appearance of the Internet has brought unprecedented changes to people's way of life, which the people of information retrieval effect are particularly important. With the appearance of Web2.0 technology, the dramatic changes in the flow of information. This thesis starts from the user interest under the network environment, the problem of information exchange and communication mode of university research under the network environment.

\section{The students' information demand under the network environment}

Under the network environment, analysis of students' information needs can begin from the aspects of information demand and information demand content form two.

Analysis for information demand investigation content, mainly from the students' online behavior, the main content of information needs can be divided into academic and nonacademic information. The main thesis is the academic information and counseling books, textbooks reflect the students' studying professional knowledge information. Rather than academic information including news, enrollment and employment, entertainment, policies and regulations, financial, commodity information, life, health, health and life are closely related to a variety of information. Different information acquisition in different ways. For the academic information, the library can basically meet the demand (including paper and network resources), while for the nonacademic information, at present the library cannot meet the students' information demand. Actually, although here is divided into nonacademic information, but this part of the information but with the life of students and learning are closely related, therefore, should cause enough attention.

Table 1 Monitoring of the Website Running Status in 2003-2010

\begin{tabular}{ccccccc}
\hline & Number & $\begin{array}{c}\text { Proportion } \\
(\%)\end{array}$ & Number & $\begin{array}{c}\text { Proportion } \\
(\%)\end{array}$ & Number & $\begin{array}{c}\text { Proportion } \\
(\%)\end{array}$ \\
\hline $\begin{array}{c}\text { Excellent } \\
(100-90 \%) \\
\text { Good }\end{array}$ & 317 & 12 & 157 & $16 \%$ & 474 & $13 \%$ \\
$\left(\begin{array}{c}89-80 \%) \\
\text { Medium }\end{array}\right.$ & 1283 & $47 \%$ & 639 & $63 \%$ & 1922 & $51 \%$ \\
$\quad(79-50 \%)$ & 292 & $11 \%$ & 150 & $15 \%$ & 442 & $12 \%$ \\
$\quad \begin{array}{c}\text { Fail } \\
(\text { Less than 49\%) }\end{array}$ & 205 & $7 \%$ & 34 & $3 \%$ & 239 & $6 \%$ \\
Unable to open & 625 & $23 \%$ & 31 & $3 \%$ & 656 & $18 \%$ \\
\hline
\end{tabular}


Analysis for the mode of information demand, mainly from the following several aspects to analyze: access to information needs, information needs, information exchange requirements, consulting information needs.

(1) Access to information demand. Under the network environment, obtain the direct needs of information including retrieval and demand access to various information cues acquire consciousness of original information.

(2) Information needs. Information needs to other individuals or external release, transfer related information needs, including foreign publish research, publish business information, publish the relevant data.

(3) The exchange of information needs. The exchange of information needs, is a kind of two-way communication needs, namely between the information communication and exchange with others or external demand.

(4) Information needs. Information needs of college students, although the percentage of the minimum, but still can not be ignored. Information needs of college students, including training consulting, abroad consulting, PubMed counseling, shopping advice, psychological counseling, job search consulting, knowledge difficult consultation etc..

Demand information exchange is one of the most pressing needs of students. Communication can be both the reality of face to face communication; also can be in the virtual network communication, no matter what kind of communication way embodies the transfer and sharing of information. Different from the traditional face to face communication under the environment of network communication, it needs the help of a tool of communication, and the types of network to provide communication tool, not a variety of characteristics. This is caused by the attraction of the network communication tool for different readers are different.

\section{Range of use compared to various network communication tools and effects}

Have different characteristics for different kinds of network tools, and according to the different characteristics with user groups and different scope of application. From the early email, MSN to the later blog, RSS to SNS, the popular micro blogging site, can be said that the development of colleges and universities are very concerned about these communication tools.

Table2. the Plan of Excellent Courses Wet site Construction

\begin{tabular}{|c|c|}
\hline The contents of plan & Excellent course website updating and maintenance \\
\hline Objective to (cause) & $\begin{array}{c}\text { Web course content lag, lack of effective learning related data link, website resources courses } \\
\text { share limited }\end{array}$ \\
\hline $\begin{array}{l}\text { Implementation of the } \\
\text { plan }\end{array}$ & Exquisite course website designer or maintenance \\
\hline Execution time & At the end of each quarter \\
\hline $\begin{array}{l}\text { The place of } \\
\text { execution }\end{array}$ & Exquisite course website (Webpage) \\
\hline Methods and steps & $\begin{array}{l}\text { The first step, excellent course team in-depth investigation, understand the main problems } \\
\text { existing in the course website portal; } \\
\text { The second step, the quality course website designers or maintenance examination site situation, } \\
\text { summed up the existing main problems analysis: } \\
1 \text { whether the normal operation of the system; } \\
2 \text { interface design is scientific and reasonable; } \\
3 \text { navigation design is clear; } \\
4 \text { interaction whether to break the limitation of time and space; } \\
5 \text { study tested whether sound; } \\
6 \text { curriculum resources are available, including teaching courseware, lesson plans, video, } \\
\text { material resources etc.. } \\
\text { The third step, excellent course team focused, induction problems, to discuss the } \\
\text { countermeasure; } \\
\text { The fourth step, the effective update course website according to the measures proposed by the } \\
\text { curriculum team and maintenance. }\end{array}$ \\
\hline
\end{tabular}




\section{The establishment of the library is the information exchange and dissemination of the main body position}

BBS forum technology, compared with traditional static Webpage in interactive performance has been greatly improved, but because BBS is a free exchange of public places, to is a loose group, in the use of the content of the post is difficult to guarantee the quality, the user is not easy to manage their own information.

MSN, QQ is the instant communication software, they can facilitate communication between people, the main application is a reference in the library, simulation implementation of on-site face-to-face communication network. The disadvantage is the exchange of both sides must be online at the same time, and, if more reference staff, will cause the answer personnel is not convenient to reply in a timely manner, the instant is greatly reduced.

$\mathrm{E}$ - mail is a network of traditional letters, also is mainly applied to library reference etc.. It can make up the shortage of instant communication software; meet the staff of different time difference in communication. Can be convenient for readers to question, at the same time, respondents may have enough time to carry out a detailed statement on the question asked.

Blog is a network diary, along with the accumulation of knowledge and ideas, Blog into knowledge management system of their own easy to use. People can write articles in the Blog, these articles posted in reverse order according to the date and year, also support the classification function, easy to own to the organization and management of information. Moreover, easy to form a collective creation of a particular theme or public interests based on the field is a concentration of divergent thinking is also thought to. However, Blog only individual viewpoint elaboration is not conducive to the exchanges between the groups, not easy to efficiently manage the thread.

SNS, full name Social Networking Services, that is, social networking services, specifically designed to help people build a social network of Internet application services. This kind of website is currently among college students more popular website, online students will spend some time browsing friends information, view and share a good article, multimedia data and other information, so this part of the website has become an important channel for college students to acquire information. However, similar to the Baidu know, sharing this information on the website involves all aspects of life, sometimes users spend a lot of time to find the needed information.

Micro Bo (Micro Blog) is a kind of informal Mini blog, a form of Web2.0, is a system similar to the blog can timely release news. Different from previous blog, it allows users to post short messages to individual micro blogging via cell phone, IM software, Email and Web, the content of the text is usually limited to 140 characters (70 bit) within. In this way, who can be very convenient to the reader's present state through the micro Bo form, to spread out the most short time? On the contrary, can also convenient and flexible to obtain a variety of user information. This makes it become a popular tool for communication network.

\section{Conclusions}

Information exchange and transmission mode of the rapid development of the network from the aspects of the impact of the traditional university, in this context, the library should keep the status of information focus, to attract more readers to use the library, we must understand the network environment, students' information demand, the operation characteristics of social networking site research, analysis of the characteristics of network communication many tools, to adopt advanced technology to provide readers with better service. To the characteristics of service characteristics of the library and the network communication tools combine to provide more convenient and efficient information for readers to access and exchange of information sharing space.

Of course, this process needs to achieve school support from policy, technology, personnel and other aspects, also needs the joint cooperation of various departments, especially needs the 
participation of teachers and students. Only in this way, set up facilities conforms more to the needs of teachers and students.

\section{References}

[1]Jia Hongtao. Problems and Suggestions of the Excellent courses' Sharing Quality Educational Resources under the Perspective of the Systematic Theory [J].Imparting knowledge and educating people, 2009 (21): 44-46.

[2]Yan Shanmin. the Difficulties and Breakthrough of College High-quality Course Websites[J]. Journal of Xuzhou Normal University(Educational Sciences Edition),2010(11):23-26.

[3]Liang Rui,Xiang Guoxiong. Analysis of Modularize-construction and Running Quality of High-quality Course[J]. Open Education Research, 2008(2):20-27.

[4] Zhang Jianian, Li Lingyun,Sun Zhenxiang. On the Construction, Application and Evaluation of Top-quality Course in View of thePerformance[J]. China Educational Technology, 2014(7):113-118.

[5]Shao Xiwu,Wang Haiyan, Shao Xiwen. Study on the Construction of the Excellent courses under the Perspective of the Model Reference Method[J]. Modern Education Science, 2009(5):111-113.

[6] Gao Dan, Li Guojie. Interior Monitoring System Building of Teaching Quality in Universities Based on the PDCA Principle [J].China Agricultural Education,2010(4):32-34,42.

[7] Li Bo. PDCA Cycle Theory Used in the Teaching Quality Management System of Universities[J]. Modern Education Science,2010(3):52-53.

[8]Wang Renhuo, Tang Anguo. Study on Sustainable Development of Excellent Courses Constuction in Universities [J].China Adult Education,2010(11):44-47. 